\title{
Risk of cancer in a large cohort of nonaspirin NSAID users: a population-based study
}

\author{
HT Sørensen ${ }^{*, 1,2}$, S Friis ${ }^{3}$, B Nørgård', L Mellemkjær ${ }^{3}$, WJ Blot ${ }^{2,4}$, JK McLaughlin ${ }^{2,4}$, A Ekbom and JA Baron $^{6}$ \\ 'Department of Clinical Epidemiology, Aarhus University and Aalborg Hospital, Vennelyst Boulevard 6, Building 260, DK-8000 Aarhus C, Denmark; \\ ${ }^{2}$ Department of Medicine, Vanderbilt University Medical Center and the Vanderbilt-Ingram Cancer Center, Nashville, TN, USA; ${ }^{3}$ Institute of Cancer \\ Epidemiology, The Danish Cancer Society, Strandboulevarden 49, DK-2 100 Copenhagen $\varnothing$, Denmark; ${ }^{4}$ International Epidemiology Institute, Ltd, 1455 \\ Research Blvd., Suite 550, Rockville, MD 20850, USA; ${ }^{5}$ Unit of Clinical Epidemiology, Department of Medicine, Karolinska Hospital, Box 281 , SE- I 7 I 77 \\ Stockholm, Sweden; 'Departments of Medicine and Community and Family Medicine, Dartmouth Medical School, Hanover, NH 03756, USA
}

There is increasing evidence of an inverse association between use of nonsteroidal anti-inflammatory drugs (NSAIDs) and risk of colorectal cancer. However, data regarding other cancer sites are limited. Using data from the population-based North Jutland Prescription Database and the Danish Cancer Registry, we compared cancer incidence among 172057 individuals prescribed nonaspirin NSAIDs with expected incidence (based on county-specific cancer rates) during a 9-year study period. A total of 608 I incident cancer cases were diagnosed among NSAID users vs 5722 expected (standardised incidence ratio (SIR) I.I, 95\% confidence interval (CI) I.0- I.I). The SIRs for colon and rectal cancer among persons who obtained 10 or more prescriptions were 0.7 (95\% $\mathrm{Cl}$ 0.6-0.9) and 0.6 (95\% Cl 0.4-0.9), respectively. Similarly, reduced risk estimates were found for stomach (SIR 0.7, 95\% CI 0.4- I.I) and ovarian cancer (SIR 0.7, 95\% Cl 0.4-1.0). Standardised incidence ratios for other cancers among those with 10 or more prescriptions tended to be close to I.0, except for lung, kidney, and prostate cancers with SIRs of I.3 (95\% Cl I.I - I.6), I.4 (95\% Cl $0.9-2.1$ ), and I.6 (95\% Cl I.3-2.0), respectively. We found protective associations of NSAIDs against colon, rectal, stomach, and ovarian cancer. Reasons for the increased risk for some cancer sites are not clear.

British Journal of Cancer (2003) 88, 1687 - 1692. doi:I0.1038/sj.bjc.6600945 www.bjcancer.com

(C) 2003 Cancer Research UK

Keywords: NSAIDs; epidemiology; risk; prevention

There is substantial evidence of an inverse association between use of nonsteroidal anti-inflammatory drugs (NSAIDs) and the risk of colorectal cancer (Kune et al, 1988; Rosenberg et al, 1991, 1998; Thun et al, 1991, 1993; Suh et al, 1993; Muscat et al, 1994; Peleg et al, 1994; Schreinemachers et al, 1994; Giovannucci et al, 1995; Smalley et al, 1999; Baron and Sandler, 2000; Coogan et al, 2000; Langman et al, 2000; Rodrigues and Huerta-Alvarez, 2001). A protective effect was initially observed in experimental studies and has been seen in epidemiologic studies of both cohort and casecontrol designs. The mechanisms underlying any chemopreventive effect of NSAIDs are not clear, but inhibition of cyclooxygenase 2 (COX-2) is a prominent candidate (DuBois and Smalley, 1996; Kawamori et al, 1998; Jones et al, 1999; Morris et al, 2001).

There have been relatively few studies of possible effects of NSAID use on the risk of other cancers, although protective effects for oesophageal and stomach cancers have been reported (Thun et al, 1993; Funkhouser and Sharp, 1995; Garidou et al, 1996; Farrow et al, 1998). In contrast, a recent study reported an increased risk of pancreatic and prostate cancer among NSAID users (Langman et al, 2000). Data regarding the risk of lung,

*Correspondence: Dr HT Sørensen, Department of Clinical Epidemiology, Vennelyst Boulevard 6, Building 260, DK-8000 Aarhus C, Denmark; E-mail: hts@soci.au.dk

Received 5 December 2002; revised 26 February 2003; accepted 28 February 2003 breast, and ovarian cancer among NSAID users are conflicting (Peto et al, 1988; Paganini-Hill et al, 1989; Schreinemachers and Everson, 1994; Egan et al, 1996; Harris et al, 1996, 1999; Cramer et al, 1998; Akhmedkhanov et al, 2001; Moysich et al, 2001; Meier et al, 2002).

We have therefore linked the Pharmaco-Epidemiological Prescription Database in North Jutland County and the Danish Cancer Registry to examine cancer incidence in a large population-based cohort of NSAID users.

\section{METHODS}

The study was carried out within the population of North Jutland, a Danish county with nearly 500000 inhabitants. The details of the study design have been described earlier (Friis et al, 2003). The county is served by pharmacies equipped with a computerised accounting system from which data are sent to the Danish National Health Service, which refunds patients part of the costs associated with the purchase of drugs, including NSAIDs, prescribed by doctors, and the prescription data are transferred to the Pharmaco-Epidemiological Prescription Database (Gaist et al, 1997; Sørensen et al, 2000), including the customer's unique civil registry number, the type of drug prescribed (Gaist et al, 1997; Sørensen et al, 2000), and the date of prescription. The unique civil registry number ensures that complete individual prescription histories can be established. 
The Prescription Database was used to identify NSAID prescriptions for 190753 county residents between 1 January 1989 and 31 December 1995. The identified prescriptions were for the following NSAIDs: azapropazone, diclofenac, etodolac, fenbufen, fenoprofen, flubiprofen, ibuprofen, indomethacin, ketoprofen, ketorolac, nabumetone, naproxen, phenylbutazone, piroxicam, proquazon, sulindac, tenoxicam, tiaprofenic acid, tolfenamic acid, and tolmetin. In Denmark, all NSAIDs can be obtained only by prescription, except for aspirin and low doses of ibuprofen.

Overall, $7060(3.7 \%)$ of the identified persons prescribed NSAIDs were excluded from the study cohort because of (i) residency outside the county of North Jutland at the date of prescription $(n=6272)$; (ii) invalid civil registry number $(n=54)$; (iii) death prior to or at the date of prescription $(n=55)$; (iv) parent (of patient) registered as customer $(n=574)$; or (v) age below 16 years $(n=105)$. After these exclusions, $183693(96.3 \%)$ persons were left for subsequent record linkage.

The study cohort was linked to the files of the Danish Cancer Registry and subjects with a cancer diagnosis, except nonmelanoma skin cancer, prior to the date of first recorded prescription for NSAID $(n=7403 ; 3.9 \%)$ were excluded from the analyses. The follow-up period began 1 year after the date of the first recorded NSAID prescription and ended on the date of first primary cancer diagnosis (except nonmelanoma skin cancer), date of death, emigration, or 31 December 1997, whichever occurred first. Data on death for subjects who died during follow-up were obtained through linkage to the National Mortality Files. To reduce any bias introduced by the inclusion of patients with recent or undiagnosed cancer, we excluded the person-time and cancer experience in the first year of follow-up after the first NSAID prescription, involving 4233 persons $(2.2 \%)$ who had a cancer diagnosis $(n=1597)$ or died ( $n=2636)$ within the first year of follow-up. After these exclusions, the study cohort included 172057 (90.2\%) individuals.

The number of cancer cases observed among users of NSAIDs was compared with the number expected, based on county-specific cancer incidence rates from the Danish Cancer Registry. Expected numbers of first primary cancers in the study cohort were calculated by multiplying the number of person-years of the cohort members (in sex groups and 5-year age groups) by the corresponding 5-year age group and calendar-year-specific incidence rates of first primary cancers for all inhabitants of North Jutland county who had not received a prescription for an NSAID. The standardised incidence ratio (SIR) was calculated as the ratio of the observed to the expected number of cancer cases. We also computed SIRs stratified by number of prescriptions for NSAIDs. For these analyses, the person-time experience of the study subjects was distributed among four categories of prescription frequency $(1 ; 2-4 ; 5-9$; or $\geqslant 10$ prescriptions) with follow-up for cancer beginning on the date of the first prescription within the given category. We also performed a test for trend in SIRs with the number of prescriptions. The statistical methods employed assume that the observed number of cases of cancer in any specific category followed a Poisson distribution. We calculated $95 \%$ confidence intervals (CI) for the SIR from an accurate asymptotic approximation.

\section{RESULTS}

Table 1 shows characteristics of the study cohort of 172057 persons free of cancer at the start of follow-up. The mean age at entry in the study, that is, time of the first recorded prescription for NSAIDs, was 47.2 years (standard deviation 18.6), and the mean follow-up after first prescription was 5.4 years (standard deviation 2.1, range 1-9 years), generating 751182 person-years. In all, $58 \%$ of the study subjects received two or more prescriptions for NSAIDs during the registration period, with $11 \%$ receiving 10 or more prescriptions.
Table I Characteristics of 172057 users recorded in the Prescription Database of North Jutland County, Denmark, between I January 1989 and 3। December 1995

\begin{tabular}{lc}
\hline & Number of users \\
\hline Sex & \\
Men & 78.562 \\
Women & 93.495 \\
Age at entry & \\
$<50$ & \\
$50-69$ & 99.376 \\
$\geqslant 70$ & 46.714 \\
Year of entry ${ }^{\text {a }}$ & 25.967 \\
1989 & \\
1990-1991 & 27.258 \\
1992-1993 & 51.053 \\
$1994-1995$ & 49.08 \\
Number of prescriptions & 44.666 \\
1 & \\
$2-4$ & 71.603 \\
$5-9$ & 59.964 \\
$\geqslant 10$ & 21.398 \\
\hline
\end{tabular}

${ }^{a}$ Date of first recorded prescription.

Overall, 6081 incident cancer cases were diagnosed among NSAID users $v s 5722$ expected, yielding an SIR of 1.1 (95\% CI: 1.01.1) (Table 2). Among the 23 specific types of cancer listed in the table, the SIRs for all, but five, fell between 0.8 and 1.2. For gastrointestinal cancers, the SIRs among NSAID users were 0.9 (95\% CI $0.8-1.0)$ for colon cancer, 0.9 (95\% CI $0.7-1.0)$ for rectum, 0.8 (95\% CI $0.6-1.1)$ for oesophagus, 0.9 (95\% CI $0.8-1.1$ ) for stomach, and 1.1 (95\% CI $0.9-1.2)$ for pancreas cancer. Increased SIRs were found for cancers of the prostate (SIR, 1.3; 95\% CI 1.2-1.5), kidney (SIR 1.2; (95\% CI 1.0-1.5), and for multiple myeloma (SIR, 1.6; 95\% CI $1.2-2.0$ ), while a reduced risk of cervical cancer was seen (SIR, 0.6; 95\% CI 0.5-0.8). The results for site-specific cancers were comparable in men and women (data not shown).

Table 3 presents results stratified by number of prescriptions for cancers of the gastrointestinal tract, the sites of a priori interest. For colon, rectum, and stomach cancers, the lowest SIRs $(0.7,(95 \%$ CI 0.6-0.9); 0.6, (95\% CI 0.4-0.9) and 0.7, (95\% CI 0.4-1.1), respectively) were found among persons who obtained 10 or more prescriptions.

Results of similar analyses for other cancer sites are presented in Table 4. The SIRs for prostate cancer increased with increasing numbers of prescriptions, with an SIR of 1.6 (95\% CI 1.3-2.0) among those with 10 or more prescriptions. Among persons who obtained 10 or more prescriptions, the SIR for cancer of the ovary was decreased (SIR 0.7, 95\% CI 0.4-1.0), while for cervical cancer, there was no evidence of decreasing SIRs with increasing prescriptions, and for breast cancer the risk estimates were all close to unity. For lung, bladder, and kidney cancer, we found SIRs above 1.0 in almost all categories of prescription frequency, with significant trends for all but bladder cancer. Among persons who obtained two to four or five to nine prescriptions, the SIRs for multiple myeloma were increased, although without any obvious trend with increasing number of prescriptions.

\section{DISCUSSION}

In this large population-based follow-up study, we found significantly reduced risks of colon and rectal cancers, and a trend towards a reduced risk of stomach cancer among users of nonaspirin NSAIDs who had filled 10 or more prescriptions. Overall, we found moderate increased risks of cancers of the 
NSAID and cancer

HT Sørensen et al

Table 2 Standardised incidence ratios (SIRs) and 95\% confidence intervals (Cl) for cancers of selected sites in users of NSAIDs in North Jutland, Denmark

\begin{tabular}{|c|c|c|c|}
\hline Cancer site (modified ICD-7 code) & Observed & SIR & $95 \% \mathrm{Cl}$ \\
\hline All neoplasms & 6081 & 1.1 & $1.0-1.1$ \\
\hline Men & 2709 & 1.1 & $1.0-1.1$ \\
\hline Women & 3372 & 1.1 & $1.0-1.1$ \\
\hline Buccal cavity $(140-148)$ & 98 & 0.9 & $0.7-1.0$ \\
\hline Oesophagus (150) & 43 & 0.8 & $0.6-1.1$ \\
\hline Stomach $(15 \mathrm{I})$ & $|3|$ & 0.9 & $0.8-1.1$ \\
\hline Colon (153) & 427 & 0.9 & $0.8-1.0$ \\
\hline Rectum (154) & 221 & 0.9 & $0.7-1.0$ \\
\hline Liver (I55) & 57 & 1.4 & $1.0-1.8$ \\
\hline Pancreas (157) & 149 & 1.1 & $0.9-1.2$ \\
\hline Lung, primary (162) & 692 & 1.1 & $1.0-1.2$ \\
\hline Breast (170) & 696 & 1.1 & $1.0-1.2$ \\
\hline Ovary (175) & 130 & 0.9 & $0.7-1.0$ \\
\hline Cervix uteri (179) & 72 & 0.6 & $0.5-0.8$ \\
\hline Corpus uteri (172) & 148 & 1.1 & $0.9-1.3$ \\
\hline Prostate (177) & 324 & 1.3 & $1.2-1.5$ \\
\hline Testis (178) & 45 & 1.0 & $0.7-1.4$ \\
\hline Kidney (180) & 144 & 1.2 & $1.0-1.5$ \\
\hline Urinary bladder (I8I) & 330 & 1.2 & $1.0-1.3$ \\
\hline Melanoma (190) & 167 & 1.0 & $0.8-1.1$ \\
\hline Nonmelanoma skin cancer (19|) & 1093 & 1.1 & $1.0-1.2$ \\
\hline Brain (193) & 170 & 1.2 & $1.0-1.3$ \\
\hline Non-Hodgkin's lymphoma $(200,202)$ & 148 & 1.1 & $0.9-1.2$ \\
\hline Hodgkin's disease $(201)$ & 23 & 1.5 & $0.9-2.2$ \\
\hline Multiple myeloma (203) & 78 & 1.6 & $1.2-2.0$ \\
\hline Leukaemia (204) & 123 & 0.9 & $0.7-1.1$ \\
\hline
\end{tabular}

Table 3 Standardised incidence ratios (SIRs) and 95\% confidence intervals (Cl) for cancers of the gastrointestinal tract including pancreas, stratified by number of NSAID prescriptions

\begin{tabular}{|c|c|c|c|c|}
\hline Cancer site & & Observed & SIR & $95 \% \mathrm{Cl}$ \\
\hline \multicolumn{5}{|l|}{ Oesophagus } \\
\hline \multirow{4}{*}{ Number of prescriptions } & 1 & 10 & 0.6 & $0.3-1.1$ \\
\hline & $2-4$ & 15 & 0.9 & $0.5-1.4$ \\
\hline & $5-9$ & 8 & 0.9 & $0.4-1.9$ \\
\hline & $\geqslant 10$ & 10 & 1.1 & $0.5-2.0$ \\
\hline Test for trend & & & & $P=0.21$ \\
\hline \multicolumn{5}{|l|}{ Stomach } \\
\hline Number of prescriptions & 1 & 35 & 0.8 & $0.6-1.1$ \\
\hline & $2-4$ & 58 & 1.2 & $0.9-1.6$ \\
\hline & $5-9$ & 20 & 0.9 & $0.5-1.3$ \\
\hline & $\geqslant 10$ & 18 & 0.7 & $0.4-1.1$ \\
\hline Test for trend & & & & $P=0.54$ \\
\hline \multicolumn{5}{|l|}{ Colon } \\
\hline Number of prescriptions & 1 & 130 & 0.9 & $0.8-1.1$ \\
\hline & $2-4$ & 164 & 1.0 & $0.9-1.2$ \\
\hline & $5-9$ & 66 & 0.8 & $0.6-1.0$ \\
\hline & $\geqslant 10$ & 67 & 0.7 & $0.6-0.9$ \\
\hline Test for trend & & & & $P=0.05$ \\
\hline \multicolumn{5}{|l|}{ Rectum } \\
\hline Number of prescriptions & । & 67 & 0.8 & $0.6-1.0$ \\
\hline & $2-4$ & 86 & 1.0 & $0.8-1.2$ \\
\hline & $5-9$ & 38 & 0.9 & $0.6-1.2$ \\
\hline & $\geqslant 10$ & 30 & 0.6 & $0.4-0.9$ \\
\hline Test for trend & & & & $P=0.34$ \\
\hline \multicolumn{5}{|l|}{ Pancreas } \\
\hline \multirow[t]{4}{*}{ Number of prescriptions } & I & 30 & 0.7 & $0.5-1.0$ \\
\hline & $2-4$ & 58 & 1.2 & $0.9-1.6$ \\
\hline & $5-9$ & 37 & 1.6 & $1.1-2.2$ \\
\hline & $\geqslant 10$ & 24 & 0.9 & $0.6-1.3$ \\
\hline Test for trend & & & & $P=0.16$ \\
\hline
\end{tabular}


Table 4 Standardised incidence ratios (SIR) and 95\% confidence intervals (Cl) for selected nongastrointestinal cancers stratified by number of NSAID prescriptions

\begin{tabular}{|c|c|c|c|c|}
\hline Characteristics & & Observed & SIR & $95 \% \mathrm{Cl}$ \\
\hline \multicolumn{5}{|l|}{ Lung, primary } \\
\hline \multirow[t]{4}{*}{ Number of prescriptions } & 1 & 177 & 0.9 & $0.8-1.0$ \\
\hline & $2-4$ & 241 & I.। & $1.0-1.3$ \\
\hline & $5-9$ & 135 & 1.4 & $1.1-1.6$ \\
\hline & $\geqslant 10$ & 139 & 1.3 & $1.1-1.6$ \\
\hline Test for trend & & & & $P=0.0005$ \\
\hline \multicolumn{5}{|l|}{ Breast } \\
\hline \multirow[t]{4}{*}{ Number of prescriptions } & 1 & 193 & 1.0 & $0.8-1.1$ \\
\hline & $2-4$ & 258 & 1.1 & $1.0-1.3$ \\
\hline & $5-9$ & 120 & 1.1 & $0.9-1.3$ \\
\hline & $\geqslant 10$ & 125 & 1.1 & $0.9-1.3$ \\
\hline Test for trend & & & & $P=0.21$ \\
\hline \multicolumn{5}{|l|}{ Cenvix } \\
\hline \multirow[t]{4}{*}{ Number of prescriptions } & I & 24 & 0.6 & $0.4-0.8$ \\
\hline & $2-4$ & 24 & 0.6 & $0.4-0.8$ \\
\hline & $5-9$ & 10 & 0.6 & $0.3-1.1$ \\
\hline & $\geqslant 10$ & 14 & 0.9 & $0.5-1.5$ \\
\hline Test for trend & & & & $P=0.24$ \\
\hline \multicolumn{5}{|l|}{ Ovary } \\
\hline \multirow[t]{4}{*}{ Number of prescriptions } & 1 & 34 & 0.7 & $0.5-1.0$ \\
\hline & $2-4$ & 53 & 1.0 & $0.8-1.3$ \\
\hline & $5-9$ & 26 & 1.1 & $0.7-1.5$ \\
\hline & $\geqslant 10$ & 17 & 0.7 & $0.4-1.0$ \\
\hline Test for trend & & & & $P=0.99$ \\
\hline \multicolumn{5}{|l|}{ Prostate } \\
\hline \multirow[t]{4}{*}{ Number of prescriptions } & 1 & 87 & 1.1 & $0.9-1.4$ \\
\hline & $2-4$ & 105 & 1.3 & $1.0-1.5$ \\
\hline & $5-9$ & 61 & 1.5 & $1.1-1.9$ \\
\hline & $\geqslant 10$ & 71 & 1.6 & $1.3-2.0$ \\
\hline Test for trend & & & & $P=0.02$ \\
\hline \multicolumn{5}{|l|}{ Bladder } \\
\hline \multirow[t]{4}{*}{ Number of prescriptions } & I & 102 & 1.1 & $0.9-1.3$ \\
\hline & $2-4$ & 116 & 1.2 & $1.0-1.4$ \\
\hline & $5-9$ & 51 & 1.1 & $0.8-1.4$ \\
\hline & $\geqslant 10$ & 61 & 1.2 & $0.9-1.6$ \\
\hline Test for trend & & & & $P=0.58$ \\
\hline \multicolumn{5}{|l|}{ Kidney } \\
\hline \multirow[t]{4}{*}{ Number of prescriptions } & । & 37 & 1.0 & $0.7-1.4$ \\
\hline & $2-4$ & 46 & 1.1 & $0.8-1.5$ \\
\hline & $5-9$ & 33 & 1.8 & $1.2-2.5$ \\
\hline & $\geqslant 10$ & 28 & 1.4 & $0.9-2.1$ \\
\hline Test for trend & & & & $P=0.04$ \\
\hline \multicolumn{5}{|l|}{ Multiple myeloma } \\
\hline \multirow[t]{4}{*}{ Number of prescriptions } & I & 13 & 0.9 & $0.5-1.5$ \\
\hline & $2-4$ & 35 & 2.1 & $1.4-2.9$ \\
\hline & $5-9$ & 19 & 2.3 & $1.4-3.6$ \\
\hline & $\geqslant 10$ & 11 & 1.2 & $0.6-2.2$ \\
\hline Test for trend & & & & $P=0.28$ \\
\hline
\end{tabular}

prostate and kidney. We did not confirm a reduced risk of lung or breast cancer as reported in some studies (Schreinemachers and Everson, 1994; Harris et al, 1996, 1999; Akhmedkhanov et al, 2002). Finally, our data support a reduced risk for ovarian cancer, which has also been reported among both users of paracetamol and aspirin (Cramer et al, 1998; Akhmedkhanov et al, 2001), and we observed a reduced risk of cervical cancer, although not among those with 10 or more prescriptions. To our knowledge, this association has not been previously investigated, although an increase of COX-2 expression has been reported in cervical cancer (Kulkarni et al, 2001; Sales et al, 2001, 2002).
With few exceptions, studies with different designs and populations have shown that aspirin and other NSAIDs appear to decrease the risk of colorectal cancer by up to $50 \%$ (Baron and Sandler, 2000). The consistency of these findings and the biological mechanisms that appear to explain them (DuBois and Smalley, 1996) suggest that the association is likely to be causal. A similar protective effect has not been found for paracetamol, further indicating that the reduced risk is not because of an effect of the underlying disease (Baron and Sandler, 2000). Some studies suggest that up to 10-20 years of regular use of NSAIDs is required before a substantially decreased risk of colorectal cancer 
can be detected (Thun et al, 1993; Giovannucci et al, 1995; Baron and Sandler, 2000), although others have shown lower rates of colorectal cancer within 5 years of NSAID use (Smalley et al, 1999; Rodrigues and Huerta-Alvarez, 2001). An early stage effect appears likely, especially since aspirin has been associated with a clearly reduced risk of large-bowel adenomas that are considered a precursor of most colorectal cancers (Greenberg et al, 1993; Sandler et al, 1998). However, probably there is a threshold for the needed dose, since several studies have shown that low-dose aspirin does not have a major cancer protective effect (Friis et al, 2003).

Our data also add to the literature suggesting that NSAIDs may exert an antineoplastic effect in the stomach. However, unlike some previous investigations (Funkhouser and Sharp, 1995; Garidou et al, 1996; Farrow et al, 1998), we saw no substantial indication that NSAID use is inversely related to risk of cancer of the oesophagus.

Previous studies have not indicated a consistent association of NSAIDs with haematopoietic cancer or cancers of the urinary or genital tract (Kune et al, 1988; Paganini-Hill et al, 1989; Thun et al, 1993; Baron and Sandler, 2000). Our findings of elevated risks for cancers of the prostate, kidney, and multiple myeloma among users of only few prescriptions may indicate that NSAIDs were prescribed for alleviation of early symptoms of undiagnosed cancer. Even though we excluded the first year of follow-up, we may not have avoided this possible confounding by indication, as some of these cancers may present with long periods with uncharacteristic symptoms before diagnosis. In addition, since screening for prostate cancer has increased during the last decades, surveillance bias may have contributed to the elevated relative risk estimates for this cancer. One recent study has suggested that daily use of NSAIDs may be associated with a lower incidence of prostate cancer (Roberts et al, 2002) in contrast to our findings and data reported from Great Britain (Langman et al, 2000).

Only phenacetin-containing drugs have been causally linked to renal cancer (McLaughlin and Lipworth, 2000), but our data cannot exclude that an association with other NSAIDs may exist. Since we did not find any strong association between NSAID use and lung cancer or other smoking-related cancers, it is unlikely that cigarette smoking is responsible for the observed associations with kidney cancer (McLaughlin and Lipworth, 2000). Obesity could be a confounding factor for the latter malignancy, since it is strongly related to both kidney cancer and osteoarthritis, a common indication for NSAIDs.

Some studies have examined in detail the risk of lung cancer among NSAID (primarily aspirin) users. Two follow-up studies did not find any overall association with aspirin use, but there seemed to be an inverse association with lung cancer incidence (PaganiniHill et al, 1989) and mortality among women (Thun et al, 1993).
Two case-control studies (Rosenberg, 1995; Langman et al, 2000) reported no association between NSAIDs and lung cancer, but a third found a relative risk of 0.7 (95\% CI $0.3-1.3)$ among women taking aspirin for at least 6 months (Akhmedkhanov et al, 2002). We had no information on cigarette smoking in our population, and thus we cannot rule out that the small SIR elevations for lung cancer (similar in men and women) may be because of differential smoking rates among NSAID users.

The main strengths of our study are its large size, its populationbased design, the completeness of follow-up, and the high quality of the cancer registration (Storm et al, 1997). The use of a prescription database eliminates recall bias, which may distort findings in case-control studies. Unfortunately, we do not have information on drug use prior to 1989, but large numbers of users with repeat prescriptions suggest that many subjects were prevalent users. We also lack clinical details about the indications for NSAID use and underlying diseases. Another limitation is the relatively short follow-up period, since long-term use may be required before a reduced risk of cancer appears (Thun et al, 1993; Giovannucci et al, 1995; Baron and Sandler, 2000). From another study, with the aim to study the risk of gastrointestinal bleeding, it seems that a prescription lasts 60-90 days (Mellemkjaer et al, 2002). In addition, we were unable to control for smoking, dietary habits, alcohol intake, and other factors. Furthermore, we had no data on compliance with the prescriptions or use of over-thecounter NSAIDs. However, the fact that drug exposure was based on prescriptions actually dispensed at pharmacies and paid in part by the patients is likely to have improved compliance. In general, over-the-counter use of nonaspirin NSAIDs in Denmark is $14 \%$ of the total NSAID use (Mellemkjær et al, 2002), but over-the-counter use may be less common among persons with prescription use, so possible confounding by over-the-counter use would lead to underestimation of a reduced cancer risk associated with NSAIDs. Whatever the impact of these issues, the fact that our estimates for the effect of NSAID use on risk of colorectal cancer agree closely with previous findings tends to support the general validity of our approach.

Our study findings provide further support that NSAIDs may protect against colorectal and ovarian cancers and perhaps stomach cancer, in particular, after 10 prescriptions. The increased risk ratios observed for other cancers need to be investigated further.

\section{ACKNOWLEDGEMENTS}

The study was funded by the Danish Cancer Society (Grant No. 99 100 09), the Western Danish Research Forum for Health Sciences, and the Danish Medical Research Council (Grant No. 9700677).

\section{REFERENCES}

Akhmedkhanov A, Toniolo P, Zeleniuch-Jacquotte A, Kato I, Koenig KL, Shore RE (2001) Aspirin and epithelial ovarian cancer. Prev Med 33: $682-687$

Akhmedkhanov A, Toniolo P, Zeleniuch-Jacquotte A, Koenig KL, Shore RE (2002) Aspirin and lung cancer in women. Br J Cancer 87: 49-53

Baron JA, Sandler RS (2000) Nonsteroidal anti-inflammatory drugs and cancer prevention. Annu Rev Med 51: 511-523

Coogan PF, Rosenberg L, Louik C, Zauber AG, Stolley PD, Strom BL, Shapiro S (2000) NSAIDs and risk of colorectal cancer according to presence or absence of family history of the disease. Cancer Causes Control 11: 249-255

Cramer DW, Harlow BL, Titus-Ernstoff L, Bohlke K, Welch WR, Greenberg ER (1998) Over-the-counter analgesics and risk of ovarian cancer. Lancet 351: $104-107$
DuBois R, Smalley W (1996) Cyclooxygenase, NSAIDs and colorectal cancer. J Gastroenterol 31: 898-906

Egan KM, Stampfer MJ, Giovannucci E, Rosner BA, Colditz GA (1996) Prospective study of regular aspirin use and the risk of breast cancer. $J$ Natl Cancer Inst 88: 988-993

Farrow DC, Vaughan TL, Hansten PD, Stanford JL, Risch HA, Gammon MD, Chow WH, Dubrow R, Mayne ST, Schoenberg JB, West AB, Rotterdam H, Fraumeni JF Jr, Blot WJ. (1998) Use of aspirin and other nonsteroidal anti-inflammatory drugs and risk of esophageal and gastric cancer. Cancer Epidemiol Biomarkers Prev 7: 97-102

Friis S, Sørensen HT, McLaughlin JK, Johnsen SP, Blot WJ, Olsen JH (2003) population-based cohort study of the risk of colorectal and other cancers among users of low-dose aspirin. $\mathrm{Br} J$ Cancer 88: $684-688$ 
Funkhouser EM, Sharp GB (1995) Aspirin and reduced risk of esophageal carcinoma. Cancer 76: 1116-1119

Gaist D, Sørensen HT, Hallas J (1997) The Danish Prescription Registries. Dan Med Bull 44: $445-448$

Garidou A, Tzonou A, Lipworth L, Signorello LB, Kalapothaki V, Trichopoulos D (1996) Life-style factors and medical conditions in relation to esophageal cancer by histologic type in a low-risk population. Int J Cancer 68: 295-299

Giovannucci E, Egan KM, Hunter DJ, Stampfer MJ, Colditz GA, Willett WC, Speizer FE (1995) Aspirin and the risk of colorectal cancer in women. $N$ Engl J Med 333: 609-614

Greenberg ER, Baron JA, Freeman Jr DH, Mandel JS, Haile R (1993) Reduced risk of large-bowel adenomas among aspirin users The Polyp Prevention Study Group. J Natl Cancer Inst 85: 912 -916

Harris RE, Kasbari S, Farrar WB (1999) Prospective study of nonsteroidal anti-inflammatory drugs and breast cancer. Oncol Rep 6: $71-73$

Harris RE, Namboodiri KK, Farrar WD (1996) Non-steroidal antiinflammatory drugs and breast cancer. Epidemiology 7: 203-205

Jones MK, Wang H, Peskar BM, Levin E, Itani RM, Sarfeh IJ, Tarnawski AS (1999) Inhibition of angiogenesis by nonsteroidal anti-inflammatory drugs: insight into mechanisms and implications for cancer growth and ulcer healing. Nat Med 5: 1418-1423

Kawamori T, Rao CV, Seibert K, Reddy BS (1998) Chemopreventive activity of celecoxib, a specific cyclooxygenase-2 inhibitor, against colon carcinogenesis. Cancer Res 58: $409-412$

Kulkarni S, Rader JS, Zhang F, Liapis H, Koki AT, Masferrer JL, Subbaramaiah K, Dannenberg AJ (2001) Cyclooxygenase-2 is overexpressed in human cervical cancer. Clin Cancer Res 7: 429-434

Kune GA, Kune S, Watson LF (1988) Colorectal cancer risk, chronic illnesses, operations, and medications: case control results from the Melbourne Colorectal Cancer Study. Cancer Res 48: 4399-4404

Langman MJ, Cheng KK, Gilman EA, Lancashire RJ (2000) Effect of antiinflammatory drugs on overall risk of common cancer: case-control study in general practice research database. BMJ 320: 1642-1646

McLaughlin JK, Lipworth L (2000) Epidemiologic aspects of renal cell cancer. Semin Oncol 27: 115-123

Meier CR, Schmitz S, Jick H (2002) Association between acetaminophen or nonsteroidal antiinflammatory drugs and risk of developing ovarian, breast, or colon cancer. Pharmacotherapy 22: 303-309

Mellemkjær L, Blot WJ, Sørensen HT, Thomassen JK, McLaughlin JK, Nielsen GL, Olsen JH (2002) Upper gastrointestinal bleeding among users of NSAIDs: a population-based cohort study in Denmark. Br J Clin Pharmacol 53: $173-181$

Morris CD, Armstrong GR, Bigley G, Green H, Attwood SEA (2001) Cyclooxygenase-2 expression in the Barrett's metaplasia-dysplasiaadenocarcinoma sequence. Am J Gastroenterol 96: 990-996

Moysich KB, Mettlin C, Piver MS, Natarajan N, Menezes RJ, Swede H (2001) Regular use of analgesic drugs and ovarian cancer risk. Cancer Epidemiol Biomarkers Prev 10: $903-910$

Muscat JE, Stellman SD, Wynder EL (1994) Nonsteroidal antiinflammatory drugs and colorectal cancer. Cancer 74: 1847 -1854
Paganini-Hill A, Chao A, Ross RK, Henderson BE (1989) Aspirin use and chronic disease: a cohort study of the elderly. BMJ 299: $1247-1250$

Peleg II, Maibach HT, Brown SH, Wilcox CM (1994) Aspirin and nonsteroidal anti-inflammatory drug use and the risk of subsequent colorectal cancer. Arch Intern Med 154: 394-399

Peto R, Gray R, Collins R, Wheatley K, Hennekens C, Jamrozik K, Warlow C, Hafner B, Thompson E, Norton S (1988) Randomised trial of prophylactic daily aspirin in British male doctors. BMJ 296: 313-316

Roberts RO, Jacobson DJ, Girman CJ, Rhodes T, Lieber MM, Jacobsen S (2002) A population-based study of daily nonsteroidal anti-inflammatory drug use and prostate cancer. Mayo Clin Proc 77: 219-225

Rodrigues LAG, Huerta-Alvarez C (2001) Reduced risk of colorectal cancer among long-term users of aspirin and nonaspirin nonsteroidal antiinflammatory drugs. Epidemiology 12: 88-93

Rosenberg L (1995) Nonsteroidal anti-inflammatory drugs and cancer. Prev Med 24: 107 - 109

Rosenberg L, Louik C, Shapiro S (1998) Nonsteroidal antiinflammatory drug use and reduced risk of large bowel carcinoma. Cancer 82: $2326-$ 2333

Rosenberg L, Palmer JR, Zauber AG, Warshauer ME, Stolley PD, Shapiro S (1991) A hypothesis: nonsteroidal anti-inflammatory drugs reduce the incidence of large-bowel cancer. J Natl Cancer Inst 83: 355-358

Sales KJ, Katz AA, Davis M, Hinz S, Soeters RP, Hofmeyr MD, Millar RP, Jabbour HN (2001) Cyclooxygenase-2 expression and prostaglandin $\mathrm{E}(2)$ synthesis are up-regulated in carcinomas of the cervix: a possible autocrine/paracrine regulation of neoplastic cell function via EP2/EP4 receptors. J Clin Endocrinol Metab 86: 2243 - 2249

Sales KJ, Katz AA, Howard B, Soeters RP, Millar RP, Jabbour HN, Soeter RP (2002) Clooxygenase-1 is up-regulated in cervical carcinomas: autocrine/paracrine regulation of cyclooxygenase-2, prostaglandine receptors, and angiogenic factors by clooxygenase-1. Cancer Res 62 $424-432$

Sandler RS, Galanko JC, Murray SC, Helm JF, Woosley JT (1998) Aspirin and nonsteroidal antiinflammatory agents and risk for colorectal adenomas. Gastroenterology 114: $441-447$

Schreinemachers DM, Everson RB (1994) Aspirin use and lung, colon, and breast cancer incidence in a prospective study. Epidemiology 5: 138-146

Smalley W, Ray WA, Daugherty J, Griffin MR (1999) Use of nonsteroidal anti-inflammatory drugs and incidence of colorectal cancer: a population-based study. Arch Intern Med 159: $161-166$

Storm HH, Michelsen EV, Clemmensen IH, Pihl J (1997) The Danish Cancer Registry-history, content, quality and use. Dan Med Bull 44: $549-553$

Suh O, Mettlin C, Petrelli NJ (1993) Aspirin use, cancer, and polyps of the large bowel. Cancer 72: $1171-1177$

Sørensen HT, Olsen JH, Mellemkjær L, Thulstup AM, Steffensen FH, McLaughlin JK, Baron JA (2000) Cancer risk and mortality in users of calcium channel blockers. A cohort study. Cancer 89: 165-170

Thun MJ, Namboodiri MM, Calle EE, Flanders WD, Heath Jr CW (1993) Aspirin use and risk of fatal cancer. Cancer Res 53: 1322-1327

Thun MJ, Namboodiri MM, Heath Jr CW (1991) Aspirin use and reduced risk of fatal colon cancer. $N$ Engl J Med 325: $1593-1596$ 